\title{
EDITORIAL
}

\section{Las reformas laborales: ¡algo más que mercado!}

\section{Consejo de Redacción}

Resumen: El trabajo es una dimensión humana esencial. Para muchas personas es su forma principal, si no única, de participación en la renta y riqueza del sistema productivo, de realización personal y de inserción social. El trabajo es mucho más que mercancía, aunque también se regule en el mercado laboral. El editorial parte de una consideración personalista del trabajo humano en la perspectiva de su contribución al bien común. En la segunda parte, descriptiva, el editorial trata de las características estructurales del mercado de trabajo en España. Tras esta presentación, en el apartado tercero se analiza el comportamiento coyuntural del mercado laboral durante la crisis. En el apartado cuarto, se trata de las dos recientes reformas llevadas a cabo por los gobiernos españoles de Zapatero (2010) y de Rajoy (2012). En las conclusiones, tras una breve consideración sobre el cambio epocal de la realidad del trabajo humano, se subrayan algunos aspectos sobre la cultura social, su base moral y la ética el trabajo, el papel de la educación y las nuevas formas de pensamiento sobre el trabajo.

Palabras clave: aspectos estructurales y cíclicos, bien común, desigualdad de ingresos, mercado de trabajo, reformas laborales, trabajo, transición histórica.

Fecha de aprobación: 25 de octubre de 2017.

The labour reforms: something more than a market!

Abstracts: Work is an essential human dimension. For many people it is their main way, if not the only one, of participating in the income and wealth of the productive system, of personal fulfillment and of social inclusion. Although regulated in the labour market, work is much more than a commodity.
Les réformes du travail: quelque chose de plus qu'un marché!

Résumé: Le travail est une dimension humaine essentielle. Pour beaucoup de personnes, c'est leur forme principale, sinon unique, de participation au revenu et à la richesse du système productif, de l'épanouissement personnel et de l'insertion sociale. Le travail est beaucoup plus que la marchandise, 
The editorial takes as its starting point the personalist consideration of human labour in the perspective of its contribution to the common good. In the descriptive part, the editorial deals with the structural aspects of the labour market characteristics in Spain. Following this presentation, the third section analyses as a circumstantial aspect the labour market behaviour during the crisis. Section four deals with the two recent reforms carried outduring both Zapatero Government (2010) and Rajoy Government (2012), considered within a wider framework. Conclusions, after a brief consideration on the change of this new era in the reality of the human labour, highlight some aspects about social culture, its moral basis and ethics at work, the role of education and the new ways of thinking about work.

Key words: Structural and cyclical aspects, good common, income inequality, labour market, labour reforms, work, epochal transition. bien qu'il soit également réglementé sur le marché du travail. L'éditoriale part d'une réflexion personnaliste sur le travail humain dans la perspective de sa contribution au bien commun. Dans la partie descriptive, l'éditorial traite des caractéristiques structurelles du marché du travail en Espagne. Après cette présentation, dans la troisième section on analyse le comportement du marché du travail pendant la crise, pris comme un aspect conjoncturel. Dans la quatrième section, ce sont les deux réformes récentes menées par les gouvernements espagnols de Zapatero (2010) et Rajoy (2012) qui sont analysées, considérées dans un cadre plus large. Dans les conclusions, après un bref examen du changement $d$ 'époque dans la réalité du travail humain, certains aspects de la culture sociale sont mis en évidence, ainsi que la base morale du travail, ou l'éthique du travail, le rôle de l'éducation et les nouvelles façons de penser sur le travail.

Mots clé: aspects structurels et conjoncturels, bien commun, inégalité des revenus, marché du travail, réformes du travail, travail, transition historique.

\section{Introducción: el trabajo humano como marco de las refor- mas laborales'}

El comentario editorial que sigue pretende hacer un análisis sobre el mercado de trabajo en España. Pero el mercado de trabajo es un mercado muy peculiar. Porque el trabajo no es una mercancía más, aunque el mercado tienda tantas veces a reducirlo sólo a eso.

${ }^{1}$ RFS ha tratado en otros momentos sobre este tema directamente: El empleo en España, RFS n ${ }^{\circ} 194$ (1994); Reparto del tiempo de trabajo y lucha contra el desempleo, RFS n 210 (1998); Familia y trabajo, $R F S n^{\circ} 225$ (2002). Como otras veces, el editorial ha sido objeto de estudio y discusión en tres sesiones del consejo de redacción los días 9-VI-2017, 22-IX-2017 y 25-X-2017, en esta ocasión sin participación de personas ajenas al mismo. 
Si la afirmación de que la economía ha de estar al servicio de la persona humana y que sólo de ésta recibe su última razón de ser es válida como principio general, mucho más hay que tenerlo presente en el caso de esta institución económica que es el mercado de trabajo.

\section{I.I. El trabajo una realidad humana}

Porque el trabajo es una realidad humana. Más aún, hoy se ha convertido en un aspecto esencial de la vida de las personas. Es cierto que esto no ha sido siempre así. Pero lo es, sin duda, en la sociedad industrial y, con rasgos algo distintos, también en nuestra sociedad postindustrial.

Porque en la sociedad moderna, donde la economía es tan determinante, el trabajo es ante todo la vía fundamental de acceso a la renta producida. Gracias a ésta puede conseguir cada uno los recursos que le permiten hacer frente a muchas de sus necesidades, y desde luego a algunas que exigen ser atendidas inexcusablemente. Pero el trabajo en nuestra sociedad es más: es vía para la integración en la sociedad y, en último término, instrumento para la realización de la persona. Más aún, el trabajo es fuente de derechos, muchos de ellos característicos del reconocimiento de los derechos de las personas por el Estado social, hoy por hoy el modelo más avanzado de organización política existente. ${ }^{2}$

Y si queremos asomarnos al tema desde su reverso, miremos a la realidad del desempleo: la persona que no tiene trabajo sirve de contrapunto para calibrar lo que significa eso en la vida de una persona y las carencias que implica.

Ahora bien, contemplando el trabajo desde una perspectiva histórica pronto constatamos que el trabajo, como toda realidad humana, está sometido a una evolución continua: ni fue siempre lo que es hoy, ni fue valorado igual en todos los tiempos, ni sus funciones han sido las mismas en cualquier época histórica. Hoy consideramos trabajo a una forma muy concreta de actividad humana: es actividad productiva y remunerada, que se realiza generalmente por cuenta de otra persona. Esta concepción es la que ha servido de base para el desarrollo del derecho laboral o para la formación de las organizaciones sindicales y patronales. Pero esta concepción tiene una historia muy breve y tampoco es evidente que vaya

\footnotetext{
${ }^{2}$ En el editorial "Un sistema de economía social de mercado para una Europa solidaria, responsable y productiva", tratamos extensamente sobre el contexto, los fundamentos y el futuro del Estado social. Cfr. RFS n 67 (2012), 5-29.
} 
a mantenerse así por mucho tiempo. Ese trabajo típico de la sociedad industrial ha ido cambiando de perfil y ha visto cómo cambiaban sus circunstancias como consecuencia de los avances técnicos, especialmente de las tecnologías de la información y la comunicación. Hoy se habla ya de la cuarta revolución industrial, vinculada a la inteligencia artificial, cuando aún no hemos asimilado la tercera, la de la irrupción y uso generalizado de las tecnologías de la información y la comunicación. Es tal la incidencia de todo esto sobre el trabajo que en los comienzos del siglo XXI ya hay síntomas de cómo se van difuminando las fronteras entre trabajo y no-trabajo.

¿Qué importancia tienen estas consideraciones como pórtico de un artículo editorial sobre el mercado de trabajo? Ante todo, queremos sólo recordar que éste es un mercado donde se intercambia una mercancía que, sólo analógicamente, se puede llamar así: porque no se agota en su valor de cambio, ni es un puro medio, sino que detrás está en juego una persona, un fin en sí mismo, que se expresa como tal a través de esta actividad productiva y retribuida. En segundo lugar, que esta actividad no es secundaria o residual en la vida de las personas, sino que constituye en nuestra sociedad uno de los ejes de su desarrollo en todos los sentidos: por tanto, una sociedad sana debe ser una sociedad con empleo para todos; y no uno empleo cualquiera sino uno que sea digno de la persona humana. Por último, y si incorporamos la prospectiva indicada, la evolución del concepto mismo de trabajo debe ser tenida en cuenta, pero de forma prudencial: ni podemos pensar el presente ignorando el futuro previsible; ni podemos deslumbrarnos por el futuro del trabajo e ignorar lo que hoy, y por bastante tiempo para muchos, el trabajo seguirá siendo. Aferrarse al pasado para reproducirlo tal cual, sin querer renunciar a nada de él, no es buen camino para avanzar bien hacia el futuro.

Puesto que afirmamos que el trabajo es algo más, no es suficiente que digamos lo que no es. Ciertamente el trabajo no es simplemente y siempre una mercancía, sino que debe ser considerado desde una perspectiva personalista del bien común: somos las personas las que trabajamos para el servicio de toda la sociedad y para nuestra propia realización personal vocacional y nuestra aportación social al bien de todos y de cada uno. Pero forzoso es reconocer que el trabajo es también una realidad macro-económica que opera como una mercancía en el sistema capitalista liberal. Aun cuando concibamos y representemos el mercado como algo diferente al espacio social para el intercambio de mercancías, siempre será necesario plantearse la cuestión del significado del trabajo en el conjunto de la acción social y, en nuestro marco del sistema de economía social de mercado y del Estado de bienestar, su relevancia para las finanzas públicas. Además el trabajo es el gran medio con que cuenta el capitalismo liberal para la distribución de renta, cuestión 
como es obvio esencialísima. Y como último apunte de estas consideraciones preliminares queremos subrayar algo que condiciona fuertemente las posibilidades de una reforma laboral. Si no hay una reforma del modelo productivo y un paralelo desarrollo del sistema de economía social de mercado, la reforma laboral queda incompleta o frustrada antes de verse sus resultados, pero por su propia dinámica interna la reforma laboral es relativamente fácil de poner en marcha, mientras que las reformas del sistema de solidaridad social y del modelo productivo que condicionan y posibilitan aquélla, son más lentas y complejas.

\section{I.2. Una concepción personalista del trabajo}

La responsabilidad de todos por el bien común y la concepción personalista del trabajo humano están estrechamente vinculadas con la promoción integral de la persona y de sus derechos fundamentales, en vistas del bien común de la humanidad, también de las futuras generaciones. ${ }^{3}$

Para poder presentar una consideración personalista e integral del trabajo hemos de hacer una distinción fundamental, la que existe entre la dimensión subjetiva y la dimensión objetiva del trabajo. En sentido objetivo, el trabajo es el conjunto de actividades, recursos, instrumentos y técnicas de las que el hombre se sirve para producir. En sentido subjetivo, trabajo es la actuación humana de la persona en cuanto capaz de realizar diversas acciones que pertenecen al proceso del trabajo y que corresponden a su vocación personal, como sujeto capaz de obrar de manera programada y racional, capaz de decidir acerca de sí y que tiende a realizarse a sí mismo. La persona es, pues, sujeto del trabajo. El trabajo en sentido objetivo constituye el aspecto contingente de la actividad humana, que varía incesantemente en sus modalidades con la mutación de las condiciones técnicas, culturales, sociales y políticas. El trabajo en sentido subjetivo se configura, en cambio, como su dimensión estable, porque no depende de lo que el hombre realiza concretamente, ni del tipo de actividad que ejercita, sino sólo y exclusivamente de su dignidad de ser personal. Esta distinción es decisiva, tanto para comprender cuál es el fundamento último del valor y de la dignidad del trabajo, cuanto para desarrollar una organización de los sistemas económicos y sociales, respetuosa de los derechos humanos. La subjetividad confiere al trabajo su peculiar dignidad, que impide considerarlo como una simple mercancía impersonal de la organización productiva.

${ }^{3}$ Las reflexiones que siguen están inspiradas o extraídas del Compendio de doctrina social de la Iglesia (2004), nn. 166, 270-293, 337-338 y 351-357. 
La persona es la medida de la dignidad del trabajo. La dimensión subjetiva del trabajo debe tener preeminencia sobre la objetiva, porque es la de la persona misma que realiza el trabajo, aquella que determina su calidad y su más alto valor. Si falta esta conciencia o no se quiere reconocer esta verdad, el trabajo pierde su significado más verdadero y profundo. El trabajo humano no solamente procede de la persona, sino que está también esencialmente ordenado y orientado a la realización de la persona. Independientemente de su contenido objetivo, el trabajo debe estar orientado hacia el sujeto que lo realiza, porque la finalidad del trabajo, de cualquier trabajo, es siempre la persona. Aun cuando no se puede ignorar la importancia del componente objetivo del trabajo desde el punto de vista de su calidad, esta componente, sin embargo, está subordinada a la realización del hombre, y por ello a la dimensión subjetiva, gracias a la cual es posible afirmar que el trabajo es para la persona y no al revés, pues la finalidad del trabajo, de cualquier trabajo humano -aun el trabajo "más corriente" o más monótono, incluso el que más margina-, sigue siendo siempre la persona. El trabajo humano posee también una intrínseca dimensión social. Trabajar es trabajar con otros y trabajar para otros, hacer algo para alguien, por lo que los frutos del trabajo son ocasión de intercambio, de relaciones y de encuentro. El trabajo, por tanto, no se puede valorar justamente si no se tiene en cuenta su naturaleza social y que la familia humana de la que cada persona forma parte es heredera del trabajo de generaciones pasadas y, a la vez, artífices del futuro de todos los que vivirán después de nosotros.

\section{I.3. Prioridad de la dimensión subjetiva del trabajo humano}

El trabajo, por su carácter subjetivo o personal, es superior a cualquier otro factor de producción. Este principio vale, en particular, con respeto al capital. En la actualidad, el término "capital» tiene diversas acepciones: en ciertas ocasiones indica los medios materiales de producción de una empresa; en otras, los recursos financieros invertidos en una iniciativa productiva o también, en operaciones de mercados bursátiles. Se habla también, de modo no totalmente apropiado, de capital humano, para significar los recursos humanos, es decir las personas mismas, en cuanto son capaces de esfuerzo laboral, de conocimiento, de creatividad, de intuición de las exigencias de sus semejantes, de acuerdo recíproco en cuanto miembros de una organización. Se hace referencia al capital social cuando se quiere indicar la capacidad de colaboración de una colectividad, fruto de la inversión en vínculos socio-culturales de confianza recíproca. 
En las relaciones entre trabajo y capital destaca la prioridad del primero sobre el segundo, así como su complementariedad. El trabajo tiene una prioridad intrínseca con respecto al capital. Este principio se refiere directamente al proceso mismo de producción, respecto al cual el trabajo es siempre una causa eficiente primaria, mientras el capital, siendo el conjunto de los medios de producción, es sólo un instrumento; por ello, entre trabajo y capital debe existir complementariedad. $\mathrm{Ni}$ el capital puede subsistir sin el trabajo, ni el trabajo sin el capital.

En las relaciones entre trabajo y capital, sobre todo ante las imponentes transformaciones de nuestro tiempo, se debe considerar que el recurso principal y el factor decisivo de que disponen las personas es su misma condición humana y que el desarrollo integral de la persona humana en el trabajo no contradice, sino que favorece más bien la mayor productividad y eficacia del trabajo mismo. El valor del capital humano reside en los conocimientos de los trabajadores, en su disponibilidad a establecer relaciones, en la creatividad, en el carácter emprendedor de sí mismos, en la capacidad de afrontar conscientemente lo nuevo, de trabajar juntos y de saber perseguir objetivos comunes. Se trata de cualidades genuinamente personales, que pertenecen al sujeto del trabajo más que a los aspectos objetivos, técnicos u operativos del trabajo mismo. Todo esto conlleva un cambio de perspectiva en las relaciones entre trabajo y capital y se puede afirmar que, a diferencia de cuanto sucedía en la antigua organización del trabajo, donde el sujeto acababa por equipararse al objeto, a la máquina, hoy, en cambio, la dimensión subjetiva del trabajo tiende a ser más decisiva e importante que la objetiva.

No debe pensarse equivocadamente que el proceso de superación de la dependencia del trabajo respecto a la materia sea capaz por sí misma de superar la alienación en y del trabajo. Esto sucede no sólo en las numerosas zonas existentes donde abunda el desempleo, el trabajo informal, el trabajo infantil, el trabajo mal remunerado, o la explotación en el trabajo; también se presenta con las nuevas formas, mucho más sutiles, de explotación en los nuevos trabajos: el super-trabajo; el trabajo-carrera que a veces roba espacio a dimensiones igualmente humanas y necesarias para la persona; la excesiva flexibilidad del trabajo que hace precaria y a veces imposible la vida familiar; la segmentación del trabajo, que corre el riesgo de tener graves consecuencias para la percepción unitaria de la propia existencia y para la estabilidad de las relaciones familiares. Si el hombre está alienado cuando invierte la relación entre medios y fines, también en el nuevo contexto de trabajo inmaterial, ligero, cualitativo más que cuantitativo, pueden darse elementos de alienación, según que aumente la participación personal en una auténtica comunidad solidaria, o bien su aislamiento en un complejo de relaciones de exacerbada competencia y de recíproca exclusión. 
La dimensión creativa es, sin embargo, un elemento esencial de la acción humana, también en el campo empresarial, y se manifiesta especialmente en la aptitud para elaborar proyectos e innovar: organizar ese esfuerzo productivo, programar su duración en el tiempo, procurar que corresponda de manera positiva a las necesidades que debe satisfacer, asumiendo los riesgos necesarios: todo esto es también una fuente de riqueza en la sociedad actual. Así se hace cada vez más evidente y determinante el papel del trabajo humano, disciplinado y creativo, y el de las capacidades de iniciativa y de espíritu emprendedor, como parte esencial del mismo trabajo.

\section{I.4. La empresa, el Estado y el mercado para el bien común}

La empresa debe caracterizarse por la capacidad de servir al bien común de la sociedad mediante la producción de bienes y servicios útiles. En esta producción de bienes y servicios con una lógica de eficiencia y de satisfacción de los intereses de los diversos sujetos implicados, la empresa crea riqueza para toda la sociedad: no sólo para los propietarios, sino también para los demás sujetos interesados en su actividad. El objetivo de la empresa se debe llevar a cabo en términos y con criterios económicos, pero sin descuidar los valores auténticos que permiten el desarrollo concreto de la persona y de la sociedad. En esta visión personalista y comunitaria, la empresa no puede considerarse únicamente como una "sociedad de capitales", pues es, al mismo tiempo, una "sociedad de personas", en la que entran a formar parte de manera diversay con responsabilidades específicas los que aportan el capital necesario para su actividad y los que colaboran con su trabajo.

El Estado ha de promover políticas activas de empleo que favorezcan la creación de oportunidades de trabajo en el propio territorio, incentivando para ello el mundo productivo. El deber del Estado no consiste en asegurar directamente el derecho al trabajo de todos los ciudadanos, sino sobre todo en secundar la actividad de las empresas, creando condiciones que aseguren oportunidades de trabajo, estimulándola donde sea insuficiente o sosteniéndola en momentos de crisis. Hay que ser conscientes de que el trabajo humano es un derecho del que depende directamente la promoción de la justicia social y de la paz civil. Las organizaciones internacionales y las sindicales deben esforzarse en el establecimiento de una trama cada vez más compacta de disposiciones jurídicas que protejan el trabajo de los hombres, de las mujeres, de los jóvenes, y les aseguren una conveniente retribución.

Para promover el derecho al trabajo debe existir realmente un libre proceso de auto-organización de la sociedad como se muestra en las numerosas iniciativas, 
privadas y sociales, caracterizadas por formas de participación, de cooperación y de autogestión, que revelan la fusión de energías solidarias. Estas iniciativas se ofrecen al mercado como un variado sector de actividades laborales que se distinguen por una atención particular al aspecto relacional de los bienes producidos y de los servicios prestados en diversos ámbitos: educación, cuidado de la salud, servicios sociales básicos, cultura. Las iniciativas del así llamado "tercer sector" constituyen una oportunidad cada vez más relevante de desarrollo del trabajo y de la economía.

La acción del Estado y de los demás poderes públicos debe conformarse al principio de subsidiaridad y crear situaciones favorables al libre ejercicio de la actividad económica; debe también inspirarse en el principio de solidaridad y establecer los límites a la autonomía de las partes para defender a la más débil. La solidaridad sin subsidiaridad puede degenerar fácilmente en asistencialismo, mientras que la subsidiaridad sin solidaridad corre el peligro de alimentar formas de localismo egoísta. Para respetar estos dos principios fundamentales, la intervención del Estado en ámbito económico no debe ser ni ilimitada, ni insuficiente, sino proporcionada a las exigencias reales de la sociedad. El Estado tiene, además, el derecho a intervenir, cuando situaciones particulares de monopolio creen obstáculos al desarrollo. Además el Estado puede ejercer funciones de suplencia en situaciones excepcionales.

La tarea fundamental del Estado en el ámbito económico es definir un marco jurídico apto para regular las relaciones económicas, con el fin de salvaguardar las condiciones fundamentales de una economía libre, que presupone una cierta igualdad entre las partes. La actividad económica, sobre todo en un contexto de libre mercado, no puede desarrollarse en un vacío institucional, jurídico y político: por el contrario, supone una seguridad que garantiza la libertad individual y la propiedad, además de un sistema monetario estable y servicios públicos eficientes. Para llevar a cabo su tarea, el Estado debe contar con la oportuna legislación, pero también debe dirigir las políticas económicas y sociales, sin ocasionar un menoscabo en las diversas actividades de mercado, cuyo desarrollo debe permanecer libre de superestructuras y constricciones autoritarias o, peor aún, totalitarias.

El Estado puede instar a los ciudadanos y a las empresas para que promuevan el bien común, disponiendo y practicando una política económica que favorezca la participación de todos sus ciudadanos en las actividades productivas. El respeto del principio de subsidiaridad debe impulsar a las autoridades públicas a buscar las condiciones favorables al desarrollo de las capacidades de iniciativa individuales, de la autonomía y de la responsabilidad personales de los ciudadanos, absteniéndose de cualquier intervención que pueda constituir un condicionamiento indebido de las fuerzas empresariales. 
Los ingresos fiscales y el gasto público asumen una importancia económica crucial para la comunidad civil y política: el objetivo hacia el cual se debe tender es lograr una finanza pública capaz de ser instrumento de desarrollo y de solidaridad. Una hacienda pública justa, eficiente y eficaz, produce efectos virtuosos en la economía, porque logra favorecer el crecimiento de la ocupación, sostener las actividades empresariales y las iniciativas sin fines de lucro, y contribuye a acrecentar la credibilidad del Estado como garante de los sistemas de previsión y de protección social, destinados en modo particular a proteger a los más débiles.

\section{Las características del mercado de trabajo en España}

Más que ofrecer un diagnóstico de la crisis que suele vincularse con los altos niveles de desempleo reinantes en nuestro país, vamos a comenzar haciendo una descripción del mercado de trabajo para analizarlo más allá de la reciente crisis. ${ }^{4}$

\section{I. Aspectos estructurales ligados al mercado de trabajo}

\section{I.I. El desempleo y su evolución}

El nivel de desempleo, el paro, es insoportablemente elevado en España $\dot{¿ E s t a m o s}$ ante un fenómeno resultado de la crisis económica? Aunque la interpretación de los datos es muy compleja, se puede afirmar que estamos ante una característica de la economía española: el nivel del paro ha sido siempre superior al de muchos países de nuestro entorno y en general al de las economías avanzadas. Por ello, este aspecto lo incluimos entre las características estructurales del mercado de trabajo español.

Por otra parte, el decrecimiento o menor crecimiento de la producción, medido, por ejemplo, por el PIB, determina un aumento del paro más rápido e intenso que en otros países cercanos; ello es otra característica de la economía española. De aquí podemos concluir que el paro es un aspecto estructural del mercado; si bien, sus variaciones coyunturales explican en cierta medida los cambios de datos; por ejemplo, en el momento actual el desempleo viene determinado por las caracte-

\footnotetext{
${ }^{4}$ Cfr. los editoriales aparecidos en RFS n. 66 (2011), 621-646 y RFS n. 70 (2015), 371-394, que tratan sobre las políticas económicas de los gobiernos de Zapatero y Rajoy.
} 
rísticas de la economía española y además por la presión de la crisis económica y financiera.

Hay otros dos aspectos que, aunque no sean completamente nuevos, se han agudizado en los últimos tiempos, adquiriendo un protagonismo muy negativo. Nos referimos a:

$1^{\circ}$ ) el paro de larga duración que afecta a personas que, en el caso de las mayores, se convierte en un fenómeno crónico; estas personas con más frecuencia tienen escasa cualificación o menos capacidad de adaptación a las nuevas demandas tecnológicas;

$2^{\circ}$ ) el desempleo juvenil, en el que se incluyen bien aquellos jóvenes que acceden al mercado, o bien jóvenes que tenían contratos de poca calidad y que han "caído" en el paro; en general, estos jóvenes que engrosan el desempleo tienen escasa formación educativa o laboral.

Como se ha apuntado anteriormente, durante la crisis iniciada en 2007, el paro ha aumentado fuertemente hasta alcanzar la cifra de 6.278.200 en el primer trimestre de 2013 , lo que representaba un $26,94 \%$ de la población activa. A partir de entonces, el paro ha ido descendiendo a medida que la economía española ha entrado en una fase de crecimiento, situándose en 4.255 .000 personas en el primer trimestre de 2017 , lo que en términos relativos significa un $18,75 \%$ de la población activa.

Hemos empezado por la variable "desempleados" porque es la que tiene consecuencias económicas y sociales más graves. En la literatura económica es frecuente tratar el paro en primer lugar, analizando después otras características que se consideran las causas del mismo. Creemos, sin embargo, que hay además otros aspectos del mercado de trabajo que nos explican sus características aunque no todos tienen incidencia sobre el desempleo. Veamos a continuación unas y otras variables.

\section{I.2. Las cotizaciones sociales, el salario mínimo y el subsidio de desempleo}

Las organizaciones empresariales siempre han insistido en que la excesiva carga de las cotizaciones sociales perjudica a las empresas y afecta negativamente al empleo. 
En España, el porcentaje de cotizaciones sociales sobre el coste laboral no es muy elevado; en el conjunto de la Unión Europea (UE), la mayoría de los países tienen tantos por ciento mayores y por consiguiente son pocos los que se sitúan por debajo del español.

La distribución de las cotizaciones entre la empresa y los trabajadores es otra cuestión diferente. La parte de la empresa supera el ochenta por ciento del total; la situación de la economía española no es excepcional, pero este porcentaje es superior al de muchos países de nuestro entorno. Ciertos estudios muestran que un incremento de las cotizaciones afecta negativamente al empleo, teniendo efectos más perjudiciales para la producción si el incremento recae solamente sobre la empresa.

No se puede alcanzar una conclusión muy terminante. Parece que las cotizaciones sociales tienen algún efecto sobre el elevado paro estructural español, pero no creemos que sea una variable muy relevante. Tampoco parece que las citadas cotizaciones hayan influido en los aspectos coyunturales del paro durante la crisis reciente.

Otra cuestión cercana a la que acabamos de comentar es el salario mínimo interprofesional. Se trata de una variable que, si se mantiene sin variaciones, no tiene efectos importantes sobre el empleo; los contratos, los convenios, lo tienen en cuenta, pero este dato queda "amortizado" cuando no hay variaciones y además no parece que influya sobre el empleo. En el caso español, el salario mínimo ha sido relativamente alto en años recientes; en el conjunto de la Unión Europea, el salario mínimo español ocupa el lugar décimo en orden decreciente. Muy recientemente, se ha aprobado un incremento importante del salario mínimo. Ello ha generado rechazo en las empresas, pero parece que su efecto sobre el empleo no ha sido, hasta ahora, muy importante, salvo en algunas empresas del sector de los servicios.

El subsidio de desempleo ha sido objeto de críticas; en concreto, se mantiene que un subsidio muy elevado en comparación con los sueldos anteriores, con una duración muy larga de la protección, unido a unas políticas de empleo poco activas, puede llevar a que algunas personas quieran mantenerse en el paro. No parece razonable que estos aspectos lleven los niveles de paro a valores elevados, aunque sí pueden promover el mantenimiento de los niveles de paro en el tiempo. Por otra parte, durante la crisis se han presentado circunstancias muy negativas para algunas familias, lo que en algunos pocos casos ha exigido una prolongación de la políitica protectora; pero repetimos que, en nuestra opinión, no pensamos que el subsidio de paro no haya podido incrementar el nivel de desempleo. 


\section{I.3. La negociación colectiva y el coste del despido}

Estas dos cuestiones sí que pueden influir en el mercado de trabajo.

La negociación colectiva no tiene probablemente efectos sobre el paro estructural, pero es posible que sí afecte al nivel de los salarios, especialmente cuando esa negociación está centralizada, no adaptándose al comportamiento de la productividad en cada empresa. En el caso español, el porcentaje de trabajadores sujetos a negociación colectiva y su grado de centralización son relativamente elevados pero no se observa una presión excesiva sobre los salarios.

En cuanto al coste por despido, éste es más elevado en España que en la mayoría de los países desarrollados, siendo por tanto una de las variables que determinan el alto nivel de paro estructural. Esto se refiere lógicamente a los contratos permanentes.

Estas dos variables han ocupado un lugar central en las reformas laborales que veremos más adelante; explican por consiguiente en gran parte el comportamiento del mercado laboral durante los últimos años.

\section{I.4. Formas de contratación}

Unas de las características típicas del mercado laboral español ha sido la dualidad de la contratación, es decir, la existencia de contratos permanentes y contratos temporales. En estos últimos no existen costes de despido. Esta modalidad proporciona una mayor flexibilidad a la empresa, que puede ajustar el empleo a la situación de los mercados, reduciendo el paro estructural; por supuesto todo ello determina unos efectos negativos sobre los salarios, condiciones de trabajo, etc. En España la proporción de trabajadores con contratos temporales, o interinos, ha sido tradicionalmente muy elevada, aunque repetimos que el paro estructural debería ser menor por esta circunstancia; no estamos por lo tanto ante una explicación del alto nivel del paro estructural. A lo largo de la crisis y hasta la actualidad, esta proporción de contratos temporales ha crecido con fuerza, siendo una válvula de escape para aumentar el empleo y reducir el paro, si bien en condiciones precarias; el propio Tribunal de Justicia de la UE ha criticado los abusos que ha observado en el mercado laboral español, que por otra parte no es solamente un rasgo de las empresas privadas sino que aparece también en el terreno de las administraciones públicas. 


\section{I.5. El ejercicio del derecho a la huelga}

El derecho a la huelga está relacionado con la negociación colectiva y otros medios de negociación de las condiciones de trabajo. Ello no tiene una relación directa con el paro, aunque puede afectar a la producción económica. En España, el derecho a la huelga está muy protegido hasta el punto de que algunos autores consideran que ha llegado a transformarse en una obligación del empresario que debe permanecer pasivo ante este derecho. Se ha afirmado que la huelga no debe afectar a la vida ciudadana, lo que justificaría ciertas prácticas, tales como la contratación de otras empresas para minimizar los daños.

\section{I.6. Las desigualdades de género}

Las diferencias entre las condiciones de los empleos es también otra característica del mercado laboral español. Los menores salarios de las mujeres, las dificultades para que puedan acceder a ciertos puestos, sobre todo directivos, etc. son aspectos que indican esta desigualdad. De forma paulatina, estas diferencias se han ido reduciendo aunque todavía no se ha alcanzado una igualdad, limitada también por ciertos aspectos sociales.

Unido a todo esto, aparece la exigencia de una conciliación que permita que la actividad laboral sea compatible con la vida familiar. En años recientes se han adoptado políticas públicas y empresariales para facilitar esa conciliación.

\subsection{Aspectos estructurales ligados a las características de la economía española}

En el apartado anterior hemos visto unas características típicas del mercado laboral que en su mayor parte explican el elevado nivel del paro estructural. Se podría pensar que una reforma laboral fuese una condición necesaria y suficiente para resolver el problema, al menos en parte. Sin embargo, hay aspectos de la economía y de la sociedad españolas que también determinan la situación del mercado laboral; es difícil distinguir las condiciones implícitas del mercado de los efectos de otros fenómenos. A pesar de ello, veremos a continuación algunas de esas variables económicas o sociales. 


\subsection{La distribución sectorial de la actividad económica}

La economía española ha experimentado cambios profundos durante los últimos seis decenios: la industria, en general, y el sector agrario han perdido importancia, mientras que los servicios, sobre todo los ligados al turismo, y la industria de la construcción han crecido de forma intensa. En muchas de estas actividades el empleo tiene un carácter estacional; se trata de contratos precarios en los que el nivel exigido de formación es muy elemental. En principio, estas circunstancia no deberían llevar a un paro elevado, pero si a una rotación muy alta y sobre todo a un paro creciente cuando la producción cae, mientras que el empleo sólo se recupera parcialmente en las etapas posteriores de crecimiento. Este comportamiento del mercado laboral está muy condicionado por la citada distribución sectorial, aunque aparezca como un aspecto coyuntural.

\subsubsection{La formación y la educación}

La "oferta educativa" es inadecuada para las necesidades de las actividades productivas. Por ejemplo, el desprestigio de la formación profesional y una enseñanza universitaria muy alejada de las necesidades de las empresas...

En cuanto a la "demanda educativa", domina en nuestra sociedad el deseo de alcanzar una titulación universitaria, al tiempo que es elevado el abandono de los estudios por parte de jóvenes que han encontrado en la construcción y los servicios una salida fácil a su actividad profesional.

Estos defectos de la educación llevan al paro de larga duración y al desempleo juvenil que ya hemos visto anteriormente. También una oferta educativa más adecuada podría facilitar empleos de calidad y reducir la temporalidad.

\subsubsection{La financiación de la economía española}

La empresa y el sector familiar se han financiado en España tradicionalmente sobre todo con el crédito bancario, por lo que su porcentaje sobre la financiación total es mucho más elevado que en la mayoría de los países de la OCDE. Esto lleva a una mayor vulnerabilidad de la actividad económica. El "boom" de la construcción fue posible por su financiación por el sistema bancario, en gran parte por las cajas de ahorro. El nivel de desempleo bajó por esta razón, pero la crisis financiera llevó en el caso español a una crisis económica y a un aumento "desaforado" del paro; esto no quiere decir, sin embargo, que el paro estructural esté influido directamente por esta forma de financiación. 


\subsubsection{El comportamiento de las administraciones públicas}

Las administraciones públicas españolas no han sido demasiado eficaces, lo que unido a unos procedimientos lentos y complejos ha sido una rémora para el crecimiento de las empresas y para su funcionamiento; se ha dicho que una simplificación de los procesos sería positiva para la producción y la marcha del mercado de trabajo; sin embargo, la reforma de las administraciones públicas sigue estando pendiente. El Estado autonómico en gran parte ha complicado aún más el comportamiento del sector público, duplicando los procesos y a veces aumentando las ineficacias.

\subsubsection{El sistema fiscal}

A pesar de las múltiples reformas del sistema fiscal, éste sigue siendo poco transparente y poco "productivo". La recaudación es inferior a la que corresponde a las características del sistema, lo que determina unos déficits públicos elevados, los cuales han sido crecientes durante la crisis, dando lugar a un endeudamiento público, interior y exterior, en el que podríamos observar un caso de "crowding out", encareciendo además la financiación privada; esto último, sin embargo, se ha eliminado en gran parte por la política monetaria del Banco Central Europeo.

Estos defectos de la fiscalidad explican la limitación de las inversiones y gastos del sector público y un funcionamiento poco eficaz de la economía y del mercado laboral; ello va unido también a un volumen de economía sumergida muy elevado en comparación con muchos países europeos; este último fenómeno puede explicar que el paro estructural sea algo más reducido, aunque en todo caso afecta negativamente al mercado de trabajo.

\section{Aspectos coyunturales}

\section{I. El comportamiento del mercado laboral durante la crisis}

En el apartado anterior se han indicado, en gran parte, los efectos de la crisis económica y financiera sobre el mercado laboral. Hemos tratado de analizar los fundamentos estructurales que explican este comportamiento, que podría haber sido diferente con otra estructura económica y social. Vamos ahora a completar lo anterior indicando su evolución durante los años críticos; estos efectos son resultados de la estructura analizada, pero no solamente de ella, ya que existen causas exteriores y de otros géneros que explican también los aspectos coyunturales. 
En primer lugar, la fuerte virulencia de la crisis llevó a muchas empresas, sobre todo del sector de la construcción, a su cierre: la "mortandad" de empresas fue muy elevada. Nos podríamos preguntar si un mercado laboral más flexible hubiera limitado el cierre de empresas. Posiblemente hubiese sido así en algunos casos, pero en la mayoría hubiera sido imposible evitarlos.

Las escasas formas de adaptación de la ocupación de los trabajadores a las circunstancias del mercado llevaron a los cierres indicados; por lo que paradójicamente un sistema que se defendía como "garantista" daba lugar al incremento del paro, debido al número de empresas que cerraban. El intolerable porcentaje de desempleados, ya citado, fue el resultado.

La reducción de la población activa influyó sobre los porcentajes del paro. Esta reducción vino determinada por la salida de inmigrantes que perdieron su empleo, por la emigración de españoles y por el desánimo de personas (parados de larga duración y jóvenes), que salieron por tanto del mercado de trabajo. En sentido contrario, la incorporación de la mujer al mercado de trabajo que ya venía produciéndose desde hacía años, se intensificó por los daños sobre la economía familiar. A pesar de todos estos cambios, la población activa disminuyó durante los años en los que hubo daños más graves.

El inicio de la recuperación ha mostrado cambios importantes respecto a lo que era "normal" en el pasado: precarización de las formas de contratación, incrementos de la temporalidad, contratos además de poca calidad (contratos "basura") y reducción de los costes laborales unitarios, con un incremento de las desigualdades sobre todo las salariales.

Las prestaciones sociales han aumentado sobre todo durante los primeros años de la crisis, lo que ha afectado al déficit público. La lenta reducción del paro y el agotamiento de los periodos de cobertura han llevado a una carga menor para el presupuesto público.

Es preocupante que el desastre económico y social del desempleo no haya llevado a una mayor efectividad de las políticas activas de empleo, quizás por los límites impuestos por la reducción del déficit.

Podemos afirmar que estos aspectos de la coyuntura económica difícilmente van a llevar a una recuperación de las circunstancias anteriores a la crisis. ¡Hay situaciones que no volverán! 


\subsection{Otros aspectos: políticas públicas, avances tecnológicos}

En un editorial anterior hemos analizado la política pública durante la crisis ${ }^{5}$; no vamos a volver sobre ello; sólo nos preguntaremos si la política de austeridad tuvo efectos sobre el mercado de trabajo que hubieran sido de menor intensidad con una política más expansiva, es decir, en términos no muy precisos, una política más "keynesiana". La respuesta debe ser afirmativa; una política menos austera hubiera dado lugar a un porcentaje de paro menor, si bien hubiera ido unida a un periodo más largo de recuperación. Hubo por lo tanto una política que afectó negativamente al mercado de trabajo; no hay que olvidar sin embargo que las posibilidades del gobierno español para llevar una política de ese tipo eran bastante reducidas. Una política claramente expansiva requería un acuerdo internacional, al menos de la UE, que no existió.

Un segundo aspecto se refiere a los avances tecnológicos. Efectivamente, las nuevas tecnologías están afectando a la economía y al mercado de trabajo; éstas están en relación con la oferta educativa, la formación exigida por los nuevos empleos y la calidad de estos. Hay actividades, por ejemplo, las del sistema financiero, que están ya adoptando esas nuevas técnicas, con cambios importantes de la actividad productiva. Menos claros son los efectos de la robotización que probablemente determinará una sustitución de mano de obra no cualificada por los robots. Lógicamente habrá cambios en el mercado de trabajo que todavía no están muy claros.

\section{Las reformas laborales del mercado}

Varias han sido las normas que han regulado el mercado de trabajo en España que, como hemos visto, presenta unas características diferenciadas de las que encontramos en otros países. Nos detenemos en las dos reformas que se han acometido en los años más recientes: la impulsada por el gobierno socialista de José Luis Rodríguez Zapatero en el año 2010 y, con más detenimiento dada su mayor profundidad, la acometida por el gobierno popular de Mariano Rajoy en 2012. Ambas han tenido como objetivos reducir la dualidad del mercado de trabajo español, aumentar la flexibilidad interna de las empresas (especialmente los mecanismos existentes para reducir la jornada como alternativa al ajuste del empleo) y mejorar las oportunidades de acceso al empleo de las personas desempleadas, especialmente los jóvenes.

${ }^{5}$ Cf. RFS 70 (2015) 371-394. 
Debemos tener en cuenta que cualquier reforma del mercado de trabajo que se encamine a la consecución de estos objetivos puede enfocarse de dos formas diferentes: mediante una revisión profunda de los mecanismos de funcionamiento de dicho mercado o bien a través de reformas parciales que, manteniendo los principios fundamentales, intenten reducir los problemas detectados, especialmente la temporalidad, y favorecer los acuerdos de empresa, sin acudir a los convenios de ámbito superior. Esta segunda vía fue la seguida previamente a los años que analizamos ahora y también la opción elegida en las dos reformas que comentamos a continuación.

\section{I. La reforma del gobierno Zapatero (2010)}

Tras un debate marcado por la convocatoria de huelga general para el día 29 de septiembre de 2010, el Congreso de los Diputados aprobó definitivamente un texto que modificaba varios aspectos de la legislación laboral vigente en aquellos momentos. Las principales medidas incluidas en la norma hacían referencia a los siguientes aspectos:

Contratación temporal. Para desincentivar este tipo de contratos, se establecieron límites temporales máximos a los contratos de obra o servicio, se endurecieron las limitaciones al encadenamiento sucesivo de los contratos temporales y se aumentaron las indemnizaciones por despido en estas contrataciones.

Favorecimiento de la contratación indefinida. Para ello se extendió el contrato de fomento del empleo a los trabajadores fijos de entre 31 a 45 años que hubieran sido despedidos, se permitió utilizar transitoriamente recursos del Fondo de Garantía Salarial (FOGASA) para el pago de una parte de la indemnización por despido objetivo y se precisaron las causas de despido por razones económicas, técnicas, organizativas o de producción, intentando proporcionar mayor seguridad jurídica a las partes y facilitando su control judicial. Por ejemplo, se estableció que se pudieran despedir trabajadores por causas económicas, no sólo en caso de pérdidas, sino también cuando se previera tenerlas, o ante una persistente caída de ingresos.

Fortalecimiento de los mecanismos de flexibilidad interna (modelo alemán). Con la reforma se pretendió potenciar la reducción de jornada o la suspensión de los contratos como alternativa a la extinción de los contratos, aplicando el denominado "modelo alemán", aunque las empresas que decidieran aplicar estas suspensiones temporales (por causas económicas o de fuerza mayor) no podrían hacerlo durante un período superior a un año. Asimismo, se buscó conseguir una mayor agiliza- 
ción de los procesos negociados en las empresas para modificar las condiciones del contrato de trabajo, potenciando el uso de las medidas extrajudiciales en la solución de los conflictos, revisando las condiciones para no aplicar las condiciones de los convenios colectivos.

Mayor control a los desempleados. Se establecieron sanciones para los parados que rechazasen cursos de formación en un plazo superior a 30 días.

Absentismo. Se facilitó el despido por faltas al trabajo rebajando del $5 \%$ al 2,5\% el índice de absentismo total que puede tener una empresa y que marca el despido objetivo individual.

FogASA. Se abarató el coste del despido al establecer que el Fondo de Garantía Salarial (FOGASA), que se nutre de las cotizaciones empresariales, pagase 8 días de las indemnizaciones de despido por causas objetivas.

Cobro de prestaciones. Se estableció la garantía del cobro del salario mínimo interprofesional para aquellos trabajadores que pueden cobrar parte de su salario en especie, como ocurre con las empleadas del hogar. También se fijó que las prestaciones por desempleo parcial pudiesen ser cobradas por horas y no por días.

Negociación colectiva. La reforma consolidó la vía del "descuelgue", o posibilidad de que las empresas no apliquen determinadas cláusulas pactadas en los convenios colectivos. No obstante, la movilidad geográfica de los trabajadores debería seguir siendo negociada entre trabajadores y empresarios como hasta el momento.

Empresas de trabajo temporal. La nueva ley también modificó el papel de las empresas de trabajo temporal (Еत), considerando que la intermediación laboral era un "servicio de carácter público" con independencia del agente que la realizase.

Bonificaciones a empresas. Se aumentaron las bonificaciones a las empresas (hasta 1.400 euros durante 3 años) para las que contratasen de forma indefinida a mujeres, a mayores de 45 años o a colectivos con dificultades de empleabilidad.

Fondo de capitalización. Sobre el Fondo de Capitalización para los trabajadores (similar al del modelo austríaco, que debe servir para abonar una parte de los despidos durante la vida laboral), el Gobierno se comprometió a tramitarlo como un proyecto de ley en el plazo máximo de un año. Este fondo debería haber estado operativo el 1 de enero de 2012 y era voluntad del ejecutivo que no supusiera un incremento de las cotizaciones empresariales. 


\subsection{La reforma del gobierno Rajoy (20/2)}

En el año 2012, la situación del mercado laboral y los acuerdos con la UE llevaron a una nueva reforma del mercado de trabajo. En síntesis, con la misma se pretendía conseguir los siguientes objetivos: crear empleo, frenar la destrucción de empleo, eliminar la dualidad del mercado de trabajo, poner en marcha mecanismos de flexibilidad interna en las empresas para promover el mantenimiento del empleo, modernizar la negociación colectiva para acercarla a las necesidades de empresas y trabajadores $y$, por último, reconocer un nuevo derecho individual de los trabajadores a la formación.

Para conseguir estos objetivos se llevaron a cabo principalmente dos medidas. En primer lugar, se dio prioridad a los acuerdos de negociación colectiva a nivel de empresa sobre los establecidos en el sector o a nivel regional y se hizo más fácil que las empresas pudiesen no aplicar el convenio colectivo propio y poner en práctica medidas de flexibilidad interna como alternativa a la destrucción de empleo. En segundo lugar, las disposiciones de protección del empleo se modificaron de nuevo de manera significativa, como vemos a continuación.

Entrando en algo más de detalle, la reforma aprobada en febrero de 2012 mediante el RDL 3/2012 y posteriormente ratificada en julio mediante la Ley $3 / 2012$, se estructuró en cuatro grandes grupos de medidas: las relativas a la intermediación laboral y a la formación profesional (capítulo I); fomento de la contratación indefinida y otras formas de trabajo (capítulo II); incentivos a la flexibilidad interna en la empresa como medida alternativa a la destrucción de empleo (capítulo III); y finalmente, reducción de la dualidad laboral, con medidas que afectan principalmente a la extinción de contratos de trabajo (capítulo IV). De forma resumida, las principales medidas concretas adoptadas:

\subsection{Flexibilidad interna como alternativa a la destrucción de empleo}

Durante la crisis, las empresas españolas reaccionaron a la caída en su demanda con ajustes de sus plantillas, en vez de explorar mecanismos alternativos como suspensiones temporales de empleo, cambios en la jornada laboral o cambios en los salarios de sus trabajadores. Con estas primeras medidas el legislador intentaba remover barreras para el uso de estos mecanismos alternativos. El objetivo principal, por tanto, era conseguir que el ajuste de empleo fuera la última opción de la empresa ante cambios en la demanda. 
Para ello, se potenció la movilidad y la modificación de las condiciones de trabajo en la empresa, facilitando la adopción de cambios unilaterales en las funciones desarrolladas por los trabajadores (movilidad funcional) o en el lugar de trabajo (movilidad geográfica) y, en general, en las condiciones de trabajo, siempre que estuvieran por encima de los mínimos establecidos en el convenio colectivo de aplicación.

También se eliminó el concepto de categoría profesional pasando a considerar el grupo profesional, de definición más flexible, como único referente para la clasificación de ocupaciones. Por otro lado, se reconoció expresamente la posibilidad de modificar temporalmente la cuantía salarial cuando existiesen probadas razones económicas, técnicas, organizativas o de producción. Con la modificación introducida en esta reforma del artículo 41 del Estatuto de los Trabajadores se consideraron tales las relacionadas con la competitividad, la productividad o la organización técnica o del trabajo en la empresa.

Por último, se potenciaron las decisiones empresariales de suspensión de contratos de trabajo y de reducción de jornada frente a las de despido, eliminando la autorización administrativa previa y aprobando incentivos en materia de cotizaciones a la Seguridad Social para estas suspensiones y reducciones de jornada (las empresas tenían derecho a una bonificación del 50 por ciento de las cuotas empresariales a la Seguridad Social por contingencias comunes).

Además de éstas se introdujeron otras medidas destinadas a combatir el absentismo laboral injustificado y a reforzar los mecanismos de control y prevención del fraude en la gestión de los recursos humanos en las empresas.

\subsubsection{Modernización de la negociación colectiva para acercarla a las necesi- dades de empresas y trabajadores}

La crisis puso en evidencia la rigidez del sistema de negociación colectiva en España, pues los salarios negociados se adaptaron tarde al cambio en la situación macroeconómica ocurrido a partir del verano de 2007, contribuyendo de esta manera a la intensa destrucción de empleo que tuvo lugar a partir de finales de ese año. Asimismo, el sistema de negociación colectiva dificultaba el ajuste, rápido y proporcionado de las condiciones de trabajo, a las necesidades de la empresa. Por ello, se estimó del todo necesario alcanzar un mayor grado de descentralización en la negociación colectiva, con el objetivo adicional de fortalecer los incentivos para la movilidad de los trabajadores de sectores y empresas poco rentables a 
otras con mejores perspectivas de futuro. Para conseguir estos objetivos se desarrollaron las siguientes medidas:

- Se estableció la prioridad aplicativa incondicional del convenio colectivo de empresa para determinadas materias (tiempo de trabajo, régimen salarial, etc.).

- Se introdujo un límite a la duración de la ultra-actividad de los convenios. Los convenios colectivos expirados sólo se aplicarían mientras se renegociasen durante un máximo de un año (fueron inicialmente dos, pero la Ley los redujo a uno), salvo que se pactase entre las partes un límite superior. Cuando decayese el convenio, se aplicaría el convenio de ámbito superior, si tal convenio existiese. En todos los demás casos el Estatuto de Trabajadores era la única fuente de protección garantizada.

- Se aprobó un nuevo régimen de inaplicación temporal de las condiciones previstas en un convenio ("descuelgue"). Concretamente, se permitía el descuelgue siempre y cuando existiese un acuerdo entre la empresa y los representantes de los trabajadores. Además, la reforma introdujo nuevos mecanismos para la resolución extra-judicial de los conflictos que pudiesen surgir en la interpretación de los convenios por parte de la empresa y sus trabajadores.

Todos estos cambios, constituyeron la reforma más profunda de nuestro sistema de negociación colectiva desde su creación en los años ochenta. Sin embargo, aún quedan aspectos que se mantienen inalterados. Por un lado, se mantiene la eficacia general de los convenios, lo que evita considerar aspectos tan importantes como la representatividad de los agentes que participan en el proceso de negociación colectiva. Por otro lado, la reforma sigue sin introducir medidas para desincentivar la negociación a nivel de sector-provincia, prolongando de esta manera la atomización de la negociación colectiva que tan pobres resultados produjo en el pasado.

\subsubsection{Protección del empleo}

Antes de las reformas laborales adoptadas en España en los últimos cinco años, el nuestro era uno de los países europeos con una legislación más estricta para la protección del empleo indefinido. La reforma de 2010 ya introdujo una apreciable flexibilización en esta legislación, pero ha sido esta reforma de 2012 la que ha introducido la mayor dosis de flexibilización de los últimos años. Concretamente, las medidas introducidas por esta reforma son las siguientes: 
- Generalización de la indemnización de 33 días por año trabajado con un máximo de 24 mensualidades en las indemnizaciones por despido improcedente.

- Eliminación del denominado "despido exprés" por el cual el empresario podía despedir sin necesidad de juicio siempre que depositara en el juzgado el importe de la indemnización por despido improcedente y el trabajador aceptara dicha indemnización en el plazo de 48 horas.

- Eliminación del pago de salarios de tramitación mientras el despido está siendo considerado judicialmente.

- Modificación de los subsidios al despido introducidos en la reforma de 2010 para que quedasen sólo para los despidos clasificados como procedentes en empresas de menos de 25 trabajadores. De esta forma se equiparaba, en la práctica, el coste de despido para contratos temporales e indefinidos en empresas de menos de 25 trabajadores, algo que podría ayudar a fomentar el empleo indefinido.

- Introducción en la ley de nuevos criterios para la valoración de las causas económicas, técnicas, organizativas y productivas del despido, de cara a hacerlas más objetivas. Concretamente se permitió clasificar un despido como procedente cuando la empresa acreditase que su nivel de ingresos (ventas) había disminuido en términos interanuales durante al menos tres trimestres consecutivos.

- Supresión de la autorización administrativa en los despidos colectivos.

- Refuerzo de elementos sociales en los despidos colectivos, que tendrían que ser pactados en convenio colectivo o durante el periodo de consultas para determinados trabajadores (mayores, con discapacidad, etc.). Así, por ejemplo, las empresas que adoptasen un despido que afectase a más de 50 trabajadores deberían ofrecer un plan de recolocación.

- Nulidad del despido por errores de forma en los despidos colectivos.

La mayoría de estas medidas ayudaban a reducir el coste de despido para las empresas, fundamentalmente en los despidos individuales, pero también parece que provocaron una mayor judicialización de los mismos. Además se redujo la brecha en los costes de despido entre contratos indefinidos y temporales, al aumentar gradualmente desde los 8 a los 12 días por año trabajado (a razón de un día por año entre 2011 y 2015) la indemnización por despido en los contratos temporales, lo que junto con las medidas en materia de contratación debería lograr reducir el grado de dualidad del mercado de trabajo. 


\subsubsection{Contratos}

En materia de contratos las principales novedades fueron tres:

- Se introdujo una nueva modalidad contractual, el contrato indefinido de apoyo a los emprendedores, para empresas de menos de 50 trabajadores y con un periodo inicial de prueba de un año. Este contrato tenía los mismos costes de despido que el resto de contratos indefinidos, pero llevaba aparejados importantes incentivos en materia fiscal y de bonificaciones a la Seguridad Social.

- Se prohibió encadenar contratos temporales más allá de 24 meses y se elevó el coste de despido de dichos contratos hasta 12 días (a partir de enero de 2015).

- Se fomentó el trabajo a tiempo parcial y la regulación del teletrabajo, permitiendo la realización de horas extraordinarias de una manera más flexible, en los contratos a tiempo parcial, incluyendo las mismas en la base de cotización por contingencias comunes.

Por lo tanto, la reforma laboral no redujo el número de modalidades de contratación, como se pedía desde diversos ámbitos académicos e institucionales, sino que introdujo una nueva modalidad de contrato indefinido que ofrecía más facilidades para el despido durante los primeros 12 meses, incluso más que la actualmente existente en la contratación temporal. A cambio, no obstante, la reforma reintrodujo el límite de 24 meses, para encadenamiento de los contratos temporales.

\subsubsection{Mejora de la intermediación laboral y de la formación en las empresas}

En este grupo encontramos medidas de diferente índole como las relativas a la modificación del contrato de formación y aprendizaje, el funcionamiento de los servicios públicos de empleo, la formación de los trabajadores, las políticas activas de empleo, las agencias de colocación, etc.

Tras la aprobación definitiva y entrada en vigor de la reforma laboral en julio de 2012 , se aprobaron distintas medidas adicionales o de desarrollo de las contenidas en la propia Ley 2/2012 de 29 de junio. Una reforma sustancialmente distinta y complementaria a la anterior fue la de Presupuestos generales del Estado para el año 2012 de julio de 2012, que modificó el sistema de prestaciones por desempleo y por la que se aprobó la reducción del $60 \%$ al $50 \%$ en la cuantía de la prestación (como porcentaje de la base reguladora) a partir del séptimo mes de desempleo y se elevó el límite de edad para tener derecho al subsidio por desem- 
pleo con duración indefinida hasta la edad de jubilación de los 52 a los 55 años. Adicionalmente también se modificaron ligeramente las condiciones que debían cumplir los perceptores de prestaciones o subsidios por desempleo en términos de búsqueda de empleo de cara a mantener dichas prestaciones.

\subsubsection{Análisis de los efectos de la reforma de 2012 y valoraciones}

\subsubsection{Análisis de la reforma}

Algunas opiniones desde el ámbito académico apuntaban que la reforma estaba bien encaminada porque, además de ampliar las causas objetivas que permitían el despido procedente por motivos económicos, introducía otras vías de ajuste alternativas al despido a través de una mayor flexibilidad en salarios, horas y condiciones de trabajo. Todo esto podía ayudar a reducir el paro y a facilitar la supervivencia empresarial en situaciones de crisis. La reforma también reducía la asimetría entre trabajadores fijos y temporales y modificaba el sistema de relaciones laborales y de negociación colectiva de una forma que tenderá a hacerlo más sensible a las condiciones del mercado, lo que ayudaba a reducir la volatilidad del empleo. Por otra parte, los cambios en la normativa fueron bastante tímidos en lo que tenía que ver con la lucha contra la dualidad, mientras que, por otra parte, era posible que fuesen más allá de lo deseable al modificar a favor de las empresas el equilibrio de fuerzas en la negociación colectiva. En contrapartida, parece que los juzgados de lo social se resistieron a aplicar aspectos importantes de la reforma, limitando así su impacto efectivo.

Por otro lado, se han publicado ya algunos estudios e informes sobre los posibles efectos de la reforma laboral. Tras la publicación de la Ley 3/2012 en julio de 2012, se sucedieron diversos intentos de evaluación del impacto que la gran multitud de medidas adoptadas tuvieron sobre las principales magnitudes del mercado de trabajo en España. Parte de estos intentos fueron realizados en un plazo muy breve tras la introducción de la reforma -por lo tanto con pocos datos y dentro de un escenario recesivo-; en otros casos (los menos), las evaluaciones se hicieron con algo más de distancia. En gran medida se trata de evaluaciones macro donde el efecto de las reformas se mide por la diferencia entre la evolución observada de ciertos agregados macroeconómicos y su evolución predicha en ausencia de la reforma. De forma muy resumida, los principales resultados que se muestran en los estudios publicados pueden sintetizarse como sigue: 
- El nivel de crecimiento del PIB a partir del cual se puede empezar a generar empleo en la economía española se puede estimar en el entorno del $1-1,2 \%$, con un aumento tanto del número de los contratos a tiempo parcial como del número total de horas trabajadas.

- Se aprecia una cierta moderación en el crecimiento de la remuneración por asalariado en el sector privado de la economía con descensos en los salarios reales. La reforma laboral, junto con el acuerdo de negociación colectiva firmado unos meses antes por los agentes sociales, indujo una caída en los costes laborales unitarios.

- Los efectos de la reforma laboral sobre las tasas de contratación fueron positivos: la contratación indefinida aumentó, la transición del desempleo al empleo indefinido creció, pero el efecto en la transición al empleo temporal fue menor y no significativo en términos estadísticos. Una aportación interesante fue la distinción por tamaño de empresa en los efectos de la reforma sobre la transición del desempleo al empleo indefinido, así como sobre los flujos de contratación. Para ello se distinguía entre empresas con más o con menos de 50 trabajadores, el límite legal para poder acogerse al nuevo contrato de apoyo a los emprendedores y a la mayoría de las subvenciones y bonificaciones aparejadas a éste. Los resultados obtenidos indicaban que las cifras de aumento en el número de contratos indefinidos se debían exclusivamente a empresas de menos de 50 trabajadores.

- Tras la introducción de la reforma, la tasa de desempleo se podría reducir en un $10,5 \%$ respecto al nivel de equilibrio existente antes de la reforma y la tasa de destrucción de empleo podría caer un 7,5\%. Sin embargo, esta reforma habría de tener un coste muy importante en términos de subvenciones a la contratación. No obstante, la reducción de la tasa de paro se debía fundamentalmente a la reducción de los costes de despido, ya que las medidas de flexibilidad interna sólo tendrían impacto sobre el mismo si las empresas que adoptasen reducciones de jornada recibían una bonificación en la cotización a la Seguridad Social de los trabajadores afectados.

Además de lo anterior, ha habido otros informes y estudios que sólo presentaban evidencias provisionales sobre los primeros efectos observados tras la reforma laboral de 2012 debido a que utilizaban pocos datos o a que sólo aportaban un análisis descriptivo que no podía ser considerado como una evidencia acerca el efecto causal o de cambio de tendencia que una determinada medida hubiese tenido. Por tanto, aún quedan numerosas preguntas por ser contestadas. Desde el punto de vista académico, la prioridad es saber si la reforma laboral 
permitió la creación de más empleo y si las facilidades para la flexibilidad interna ayudaron a frenar la destrucción de puestos de trabajo. Pero el nivel de empleo y la tasa de destrucción no son las únicas variables de interés. También hay que investigar si la reforma permitió mejorar la estabilidad del empleo a través de una reducción en la tasa de temporalidad y/o un aumento en la tasa de conversión de los contratos temporales en fijos, algo que tendría que haberse manifestado también en un mejor comportamiento cíclico del empleo. Por último, aunque la reforma de la negociación planteaba retos muy importantes, habría que intentar verificar en qué medida la reforma de 2012 aceleró el ajuste salarial y en qué medida logró un mejor ajuste entre los salarios y la situación económica de las empresas.

\subsubsection{Efectos de la reforma sobre la renta y la desigualdad}

Pero, además de todo lo anterior, por otra parte hay cuestiones que merecen atención, por ejemplo, los efectos que tuvo la reforma sobre la distribución de la renta y sobre los niveles de desigualdad. Así, si bien en los últimos meses España se está beneficiando de un proceso de intensa creación de empleo, un número importante de personas sigue sufriendo especiales dificultades en su acceso al mundo laboral. Estas dificultades se expresan en largos períodos de desempleo, o en empleos cuyas retribuciones, duración y/o jornadas les mantienen en situación de pobreza laboral, el fenómeno conocido como los "working poors".

Desde el punto de vista de la distribución de la renta, además, se observaba que hay una tendencia a que disminuya la parte de la renta que corresponde a la remuneración del trabajo, básicamente sueldos y salarios, mientras que crece la proporción de la renta que tiene su origen en la propiedad de la empresa, principalmente, beneficios, intereses, etc. Es decir, se abre una brecha mayor entre las rentas del trabajo y las rentas del capital, que desequilibra los resultados de las reformas y mejoras de la producción.

A lo anterior se une un crecimiento de la desigualdad en los niveles salariales entre diversas categorías de trabajadores: por ejemplo, algunos estudios muestran que ha aumentado la divergencia entre los salarios medios de las ocupaciones denominadas "altas" (en las que se incluyen directores, gerentes y técnicos) y "bajas" (en las que se incluyen operadores y otras ocupaciones elementales); de manera similar, también ha crecido la diferencia entre los ingresos de los trabajadores con contratos de duración indefinida y los de los trabajadores con contratos de duración determinada, y de la misma forma han aumentado las divergencias por tramos 
de edad o las de los trabajadores migrantes frente a los nacionales, o las de las mujeres frente a los varones. Es cierto que estas diferencias se atenúan o incluso no se aprecian cuando, en lugar de comparar los ingresos medios, las comparaciones se hacen en términos de salarios medios por hora, lo cual señala probablemente que hay una mayor incidencia del trabajo a tiempo parcial y temporal en las ocupaciones de menor categoría profesional o con contratos temporales, un hecho que en parte se debe a las medidas establecidas por la reforma.

Todos estos fenómenos, además, se unen a un problema persistente en nuestro mercado de trabajo: la elevada tasa de parados de larga duración (a finales de 2015 , más del $12 \%$ de la población activa española llevaba desempleada más de un año; esta cifra es casi cinco veces mayor que la media de la OCDE). Se trata fundamentalmente de individuos con bajos niveles de cualificación (sin estudios más allá de la educación obligatoria) que provienen en buena parte del sector de la construcción. Durante la crisis, se han destruido en España casi tres millones de puestos de trabajo de baja cualificación y cerca de otro millón de cualificación intermedia, mientras que el número total de puestos de trabajo cualificados se ha mantenido aproximadamente constante.

La situación de la población afectada por este fenómeno no sólo no muestra una tendencia a mejorar con la incipiente recuperación económica, sino que tiende además a enquistarse. Una vez se entra en el colectivo de parados de larga duración resulta difícil salir de él, con el consiguiente riesgo de exclusión social y económica. Dado el tamaño de la población afectada, la situación constituye una auténtica tragedia social en potencia. Para evitar que ese riesgo se materialice en mayor medida de lo que ya lo ha hecho necesitamos mejorar nuestras políticas activas y de activación. No obstante, aún se necesita más investigación para determinar qué políticas de empleo pueden funcionar para qué colectivos y cuáles son las mejores herramientas de gestión para adaptar los tratamientos a las necesidades de cada individuo. Además, también hay que repensar el papel de los servicios públicos de empleo en la situación actual. Sería necesario reforzar la colaboración entre los servicios de empleo estatales y autonómicos para coordinar las políticas activas con el diseño de las prestaciones por desempleo, lo que puede redundar en significativas mejoras de eficiencia. También habría que recurrir a las agencias de colocación privadas para lidiar con una situación excepcional, y esperemos que transitoria, que excede con mucho a la capacidad de gestión de los servicios públicos de empleo.

La opinión de los sindicatos es mucho más negativa. Consideran que la reforma laboral ha llevado a un empleo precario y temporal, reducción de los salarios, 
prestaciones por desempleo que cubren cada vez a menos parados y pensiones escasas. En consecuencia, proponen la derogación de las reformas laborales. Como es lógico se refieren a toda la política de los gobiernos y no solamente a las llamadas reformas laborales propiamente dichas.

En definitiva, a pesar de los efectos positivos que ha tenido la reforma, es cierto que hay aspectos negativos que vienen de la mano del crecimiento de las desigualdades y de la existencia de diferentes colectivos desfavorecidos a los que debe darse respuesta. Así, hay propuestas de los partidos políticos a aspectos que en su opinión no han sido resueltos por las reformas. Sólo apuntaremos algunas de ellas:

1) El PSOE propone un "plan de rescate de los jóvenes" y la protección de los parados de larga duración, una reducción de la brecha salarial entre hombres y mujeres y la negociación con el gobierno y las patronales de ciertos cambios de la reforma laboral.

2) Ciudadanos propone la creación de un contrato único, un complemento salarial y la llamada "mochila austriaca".

3) La instauración de una renta básica universal es defendida por Podemos, algunos socialistas y ciertos miembros de Ciudadanos.

4) El propio gobierno, en concreto el Ministerio de Economía, propone medidas para eliminar las normas que dificultan el crecimiento de las empresas, sobre todo de las PYMES y que, en consecuencia, afectan negativamente al mercado laboral.

Otras opiniones, expuestas principalmente en los medios de comunicación, son, por ejemplo, que se debe crear más empleo de alta cualificación y de elevada productividad, que se debe priorizar el empleo sobre el sueldo y también que los salarios deben estar relacionados con la productividad más que con el nivel de precios. Estas opiniones, con frecuencia, no plantean medidas concretas para conseguir dichas mejoras.

Como vemos hay muchas críticas en relación con el mercado laboral, pero finalmente los conflictos desembocan con frecuencia en la subida de los sueldos y salarios más que en cuestiones de carácter estructural. Esto lo hemos visto con claridad durante los últimos meses. 


\section{Conclusión}

\section{I. El trabajo en una fase de transición epocal}

El Compendio de doctrina social de la Iglesia habla de una fase de transición epocal ${ }^{6}$ para referirse a los nuevos contextos en que debe acometerse una reflexión práctica y orientadora sobre el trabajo humano. Estos son sus rasgos principales. Uno de los estímulos más significativos para el actual cambio de la organización del trabajo procede del fenómeno de la globalización, que permite experimentar formas nuevas de producción, trasladando las plantas de producción en áreas diferentes a aquellas en las que se toman las decisiones estratégicas y lejanas de los mercados de consumo. Dos son los factores que impulsan este fenómeno: la extraordinaria velocidad de comunicación, sin límites de espacio y tiempo, y la relativa facilidad para transportar mercancías y personas de una parte a otra del planeta. Esto comporta una consecuencia fundamental, ya que la propiedad está cada vez más lejos de los lugares de producción y es a menudo indiferente a los efectos sociales de las opciones que realiza.

Por otra parte, si es cierto que la globalización, a priori, no es ni buena ni mala en sí misma, sino que depende del uso que se haga de ella, debe afirmarse que es necesaria una globalización de la tutela de los derechos mínimos esenciales y de la equidad. Una de las características más relevantes de la nueva organización del trabajo es la fragmentación del ciclo productivo, impulsada por el afán de conseguir una mayor eficiencia y mayores beneficios. Desde este punto de vista, las tradicionales coordenadas espacio-temporales, dentro de las que el ciclo productivo se definía, han sufrido una transformación sin precedentes, que han determinado un cambio en la estructura misma del trabajo.

Todo ello tiene importantes consecuencias en la vida de las personas y de las comunidades, sometidas a cambios radicales tanto en las condiciones materiales, cuanto en la cultura y los valores. Este fenómeno afecta, a nivel global y local, a millones de personas, independientemente de la profesión que ejercen, de su condición social o de su preparación cultural.

La reorganización del tiempo, su regularización y los cambios en curso en el uso del espacio -comparables, por su entidad, a la primera revolución industrial, en cuanto implican a todos los sectores productivos, en todos los continentes, indepen-

${ }^{6}$ Esta consideración está tomadas del Compendio de doctrina social de la Iglesia (2004), nn. 310 ss. 
dientemente de su grado de desarrollo- deben considerarse, por tanto, un desafío decisivo, incluidos los aspectos ético y cultural, en el ámbito de la definición de un sistema renovado de tutela del trabajo.

\subsection{Los condicionamientos de largo alcance para las reformas laborales}

La crisis económica y financiera que comenzó en 2007 afectó profundamente a la economía española, no sólo por el "efecto contagio", sino también por los problemas específicos de ésta, que era una economía basada principalmente en la construcción, con un número elevado de trabajadores con escasa formación, con un sistema financiero que obtenía gran parte de los recursos de mercados sobre todo internacionales, con una débil productividad de las empresas, etc. De aquí que, al "estallar" la crisis, se produjera una caída de la producción, un crecimiento insufrible del paro, problemas del sistema financiero por el cierre de los mercados, un aumento del déficit público y del endeudamiento público, etc.

Ante esto ¿se podía haber realizado una política "keynesiana"? Difícilmente, pues sus efectos, aumento del déficit público y del déficit exterior, hubieran determinado un aumento elevado de la prima de riesgo, un incremento de los costes y la quiebra de empresas. Sin embargo, una reforma aislada, por ejemplo la laboral, no hubiese sido la estrategia más adecuada. En concreto, ésta debería ir unida a medidas en el ámbito de la producción de bienes y servicios, reforma de las administraciones públicas, mayores facilidades para la creación de empresas e incluso políticas macroeconómicas que, en el caso de España, no eran posibles por lo que acabamos de comentar. Además hay que tener en cuenta que la mayoría de los cambios en las políticas citadas tienen efectos a medio y largo plazo, mientras que la reforma laboral es mucho más efectiva en un plazo más reducido. Todo esto se refiere a la economía sin adjetivos, pero que no hay que olvidar que en la Unión Europea (UE) se ha desarrollado un sistema de economía social de mercado que debería haber estado presente en las reformas citadas, lo que obligaba a ciertas decisiones acordes con el sistema, que escasamente se tuvieron en cuenta. De nuevo la incompatibilidad entre el corto y el largo plazo explica esta realidad.

En el momento en el que se tomaron las decisiones, parecía que no había más recurso que una reforma laboral que eliminase o atenuase los problemas por la vía de una devaluación interna. Fuera del euro hubiera sido posible una devaluación externa, pero ello hubiera llevado a un desequilibrio como los que se dieron en el pasado. En todo caso, el formar parte de la Unión Económica y Monetaria impedía esta "solución". En consecuencia la UE impuso unas políticas de reforma 
y una mayor austeridad fiscal que se suponía que permitirían una recuperación de la economía española. En ausencia de estas políticas se hubiera impuesto una intervención de la economía española y no solamente de las entidades financieras. Visto todo lo anterior, se podría afirmar que esta "vía" era la única posible.

España ha conocido recientemente tres reformas laborales en 1997, 2010 y 2012. Con ninguna de ellas se ha logrado modificar el modelo de empleo, pues no se ha abordado la inseguridad jurídica de la normativa contraria a la contratación estable en la pequeña empresa, ni se ha avanzado en los ajustes pactados con los trabajadores. El abuso en la temporalidad y la multiplicación de altas a la Seguridad social no sirven para facilitar la generación de trabajo estable ${ }^{7}$.

Aún así se puede considerar que las reformas tuvieron gran influencia en la recuperación de la economía española y en el descenso del paro. Así mismo, el equilibrio exterior y la mejora de la productividad de las empresas estuvieron muy relacionados con las reformas laborales. Casi todos los analistas afirman que estos resultados fueron el resultado de las reformas laborales y de otras medidas políticas.

Estas reformas sin embargo aquéllas tuvieron también efectos negativos: bajos salarios, trabajos "basura", desigualdades crecientes de renta, dualidad del mercado de trabajo, inseguridad jurídica de las normativas aprobadas, nula protección de los ajustes pactados con los trabajadores que hubieran limitado las pérdidas de empleo, mantenimiento de las desgravaciones para la creación de empleo, que elevan las altas a la Seguridad social, pero no crean empleo estable, mantenimiento de las numerosas fórmulas contractuales, etc.

Uno de los aspectos principales de la reforma se refiere a la negociación colectiva. Es cierto que era necesario un cambio de dicha negociación para conseguir una mayor flexibilización y poder adaptarse a los cambios del entorno, pero el que se realizó ha terminado resultando especialmente perjudicial para los trabajadores de las PYME cuyo poder en el ámbito de la negociación colectiva es mucho más reducido que el de los trabajadores de la gran empresa. No podemos olvidar que, en el ámbito de la negociación colectiva, la posición del empresario y de los trabajadores en las PYME y en las grandes empresas es muy distinta.

En nuestra opinión se hizo poco para reducir estos efectos negativos, por lo que es comprensible que algunos partidos políticos y sindicatos planteasen "reformar la reforma". Se pensaba que el crecimiento de la economía española resolvería

${ }^{7}$ Cfr. El País Negocios, 30-VII-2017, p. 18. 
inmediata y fácilmente estos problemas, pero hasta ahora no ha sido así. Actualmente, además de esta nueva reforma es necesario limitar o reducir esos efectos negativos. ¿QQuién podría hacerlo? Por supuesto los gobiernos pero también las propias empresas; ignorar la situación llevaría en el futuro a graves problemas sociales, e incluso políticos.

Podemos hacer, aunque sólo enunciativamente, otras consideraciones complementarias, dejando de lado los aspectos puramente técnicos relativos al funcionamiento del mercado laboral.

Por una parte, los factores culturales determinan que las mismas políticas tengan impactos diferentes en cada sociedad; por otra parte, la corresponsabilidad en este orden de otros agentes sociales, especialmente las escuelas y las universidades.

Respecto a la primera cuestión, sin desviarnos demasiado del tema, quisiéramos llamar la atención sobre el hecho de que, como muestra el caso de los países nórdicos, hay rasgos culturales que se convierten en piedras angulares del éxito de las políticas públicas. Entre los rasgos de este grupo de países cabe destacar unos elevados niveles de confianza y participación ciudadana, una sólida ética del trabajo, que convive con una gran cohesión social, que, a su vez, se ve facilitada por la responsabilidad individual y los valores familiares. Todo ello explica que en países como Dinamarca exista un gran margen de libertad económica en numerosos ámbitos; por ejemplo, no existe un salario mínimo impuesto por ley y la indemnización por despido es muy inferior a la de España, además existe la posibilidad de rescindir el contrato de los funcionarios por bajo rendimiento.

La ética del trabajo y la confianza permiten a los gobiernos desarrollar un Estado del bienestar, a cambio de impuestos elevados, en el que el riesgo de sufrir abusos o efectos no deseados derivados de los incentivos es limitado. Al mismo tiempo, estas sociedades dan un valor importante a la familia, lo que se concreta en muchos y diversos apoyos públicos y privados para conciliar la vida laboral y familiar. ${ }^{8}$

En definitiva, hay un compromiso y una corresponsabilidad efectiva de los sectores público y privado y de la propia ciudadanía, que actúan como garantes del éxito o de la mayor eficacia y eficiencia de las iniciativas y políticas llevadas a cabo en las reformas.

\footnotetext{
8 Por citar algunos ejemplos, en el ámbito público las bajas de maternidad y paternidad son amplias (52 semanas en Dinamarca, 57 en Norvega y 69 en Suecia) respetándose prácticamente la integridad de los salarios. En el sector privado encontramos que es habitual que los gimnasios dispongan de servicios de guardería.
} 
Respecto a la segunda cuestión, quisiéramos llamar la atención sobre el papel que el sistema educativo tiene en el mercado de trabajo. Son varios los estudios que, en los últimos años han puesto de manifiesto la fractura ("gap") existente entre la cualificación de la mano de obra y las competencias y habilidades requeridas por las empresas.

Éste es un tema complejo que no sólo explica un porcentaje del desempleo, sino que también afecta a los que están empleados, ya que ante la escasez de trabajo la gente está más dispuesta a aceptar ocupaciones que no se corresponden con su nivel de titulación. En la UE, alrededor del $29 \%$ de los trabajadores están "sobrecualificados", es decir, su formación es superior a la requerida para el puesto que desempeñan. A la desmotivación en el trabajo que conlleva esta situación habría que sumarle los costes al no recuperarse la inversión en formación que han realizado estas personas y el sector público, según el caso. El diálogo y la interacción entre los agentes sociales, administración, empresas, universidades, etc., es requisito imprescindible para reducir esta situación. Por otro lado, algunos expertos han criticado que el mercado laboral español "está exhausto de reformas", afirmando que la primera política de empleo es la educativa y que lo único que va a permitir en el futuro que se llegue a una mayor remuneración del trabajo es la capacitación de los trabajadores, pero no sólo desde el punto de vista de las habilidades técnicas, sino priorizando la formación y la preparación de personas, ya que estamos inmersos en un mundo cambiante en el que probablemente, muchos niños que están hoy en las guarderías harán carreras o desempeñarán trabajos que aún no existen.

En definitiva, quisiéramos destacar que en el diseño del Estado del bienestar se echa en falta la coordinación entre políticas educativas, sociales (conciliación de la vida laboral y familiar, igualdad de género, inclusión social y migraciones) y políticas de fomento del empleo, todas ellas interrelacionadas.

\subsection{Las nuevas posibilidades}

Finalmente, tampoco debemos dejar de mencionar la existencia de formas de pensamiento que, con origen en nuevas corrientes económicas o sociales, nos llevan a la consideración del trabajo en una dimensión que trasciende del ámbito puramente económico.

Ciertas corrientes de pensamiento como la llamada "economía del bien común" o también la "economía de comunión" o la "economía del don", en la que el éxito 
económico no se mide sólo por los indicadores monetarios como el beneficio financiero o el PIB, sino por el balance del bien común en el que lo importante es que las actividades tengan un carácter más social, ecológico, democrático y solidario, aunque aún presentan ciertas limitaciones para su aplicación a nivel práctico, no cabe duda de que pueden influir para conseguir que el trabajo no sea meramente una mercancía. Así, por ejemplo, desde esta vía, se aboga por llegar a que el horario de trabajo retribuido se reduzca progresivamente para conseguir tiempo para otros campos de gran importancia como el dedicado a las relaciones humanas y a los cuidados, al crecimiento personal y al desempeño de actividades en la política y el servicio público. Igualmente, se propugna que los trabajadores lleguen a contar con un "año sabático" financiado a través de un salario mínimo. La forma de repartir los beneficios o la responsabilidad social son otros rasgos destacados de estas corrientes. Es cierto que algunas veces no es fácil llevar a la práctica estas propuestas, aunque empiezan a tener una influencia creciente en ciertas sociedades.

Estamos asistiendo también a un crecimiento de lo que se ha dado en denominar "economía colaborativa", en la que gracias a internety otras tecnologías, la relación entre quien ofrece un producto y quien tiene una necesidad concreta está cambiando de manera significativa. Este modelo se basa en prestar, alquilar, comprar o vender productos en función de necesidades específicas y no tanto de beneficios económicos, de forma que en este sistema es posible que el dinero no sea el único valor de cambio para las transacciones. Así, los servicios son considerados bienes de intercambio (por ejemplo, una persona que pueda ofrecer alojamiento a otra durante unos días a cambio de unas clases de idiomas), de forma que el centro de las actividades es la colaboración y la ayuda muta.

Lógicamente, este modelo, cuya extensión aún es limitada, puede tener trascendencia sobre el trabajo, el cual se puede convertir en un servicio más a intercambiar. El imparable avance del trabajo en plataformas está poniendo en el centro del debate laboral diversos temas relacionados con esta nueva realidad económica. En el centro de este debate, la Comisión europea publicó un importante documento en el que hablaba de la existencia de una Agenda europea para la economía colaborativa y desde el punto de vista de los expertos ya se está planteando la necesidad de adaptar el Derecho de la economía para ofrecer una respuesta adecuada a esta nueva realidad. El hecho de que los servicios permanezcan en la economía informal puede llevar a una falta de protección social de las personas que trabajan de esta manera. De la misma forma, la existencia de plataformas que actúan como intermediarios entre usuarios y prestadores de servicios, que son realmente autónomos, conlleva la necesidad de intervenir para garantizar 
condiciones dignas y la estabilidad y seguridad económica de los trabajadores, evitando el riesgo de precarización.

Para concluir queremos subrayar dos afirmaciones. Por un lado, la reforma del mercado de trabajo ha sido la única vía que se ha utilizado para superar la crisis financiera y económica de este decenio, cuando hubiesen sido necesarias -y siguen siéndolo- otras políticas públicas más profundas y de alcance más duradero y complementario.

Por otro lado, no dejaremos de defender y promover una visión integral y personalista del trabajo como realidad humana. Lo hacemos con la afirmación recogida en un número anterior de esta revista?:

Los procesos de producción y circulación deben asegurar a los trabajadores un trabajo digno, participativo, adaptado a una vida familiary cultural, favoreciendo sus capacidades y asegurando una existencia material adecuada. Las prácticas contrarias se oponen al Bien Común de la Humanidad y al Buen Vivir.

Texto disponible en inglés en www.revistadefomentosocial.es

${ }^{9}$ RFS 72 (2017) 313. 